بحث مقارن لاراسة الأعراض السيكوسوماتية لاي عينة من الطالبات المغتربات وغير المغتربات إعداد الباحثة / نهاد سيد عفيفي قاسم نوار

$$
\text { إثراف }
$$

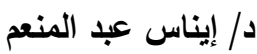

مدرس علم النفس بكلية الآداب

جامعة عين شمس
الأستاذ الاكتور / محمود السيد أبو النيل أستاذ علم النفس بكلية الآداب جامعة عين شمس

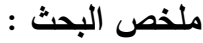

تتاول البحث الحالي الأعراض السيكوسومانية لاي الطالبات المغتربات و غير المغتربات باستخدام قائمة كورنل لنواحي العصابية و السيكوسوماتية وقد أشنارت نتائجه إلي التالي : أنشارت نتائج التحليلات الإحصائية التى أجريت باستخدام اختبار مان-ويتتى أثنارت إلى وجود فروق ذات دلالة إحصائية بين المجموعتين ( الطالبات الريفيات المغتربات بالمدينة الجامعية ، والطالبات الحضريات غير المغتربات ) علي كل من المقاييس الفرعية للسمع و الابصار و الهيكل العظمي عند مستوي دلالة ا.،.. ، والجهاز الهضمى والجلد والجهاز العصبى و البولي النتاسلي و التعب و القلق عند مستوي دلالة ه.،. ، والتوتز والدرجة الكلية عند مستوي دلالة ا.....

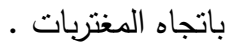


-لقد بلغت مشكلة الاضطرابات السيكوسوماتية حجما كبيرا حيث ارتبط انتثارها بالحضارة الحديثة والتحديث ، فبالرغم مما ينتشر بين الناس اليوم من اهتمام ورعاية فى التتشئة والصحة والتعليم ، والتى لم تكن ميسرة فى الماضي ومما حدث من

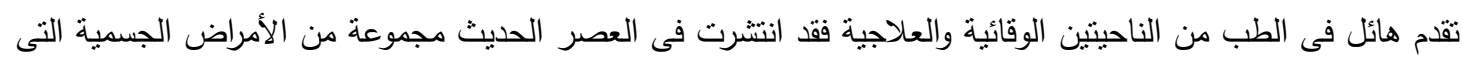

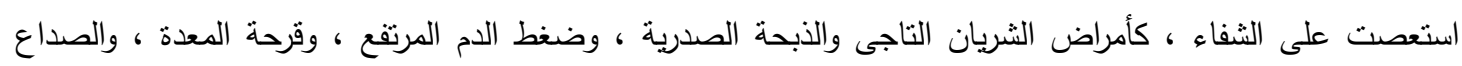



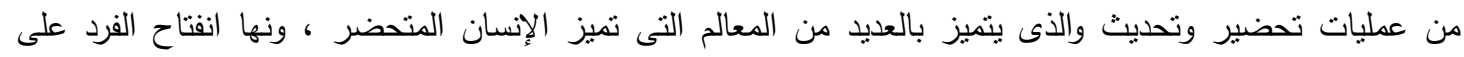

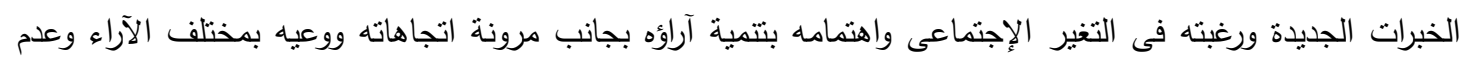

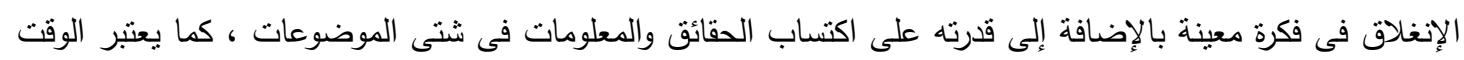



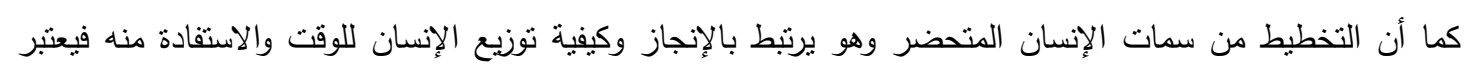



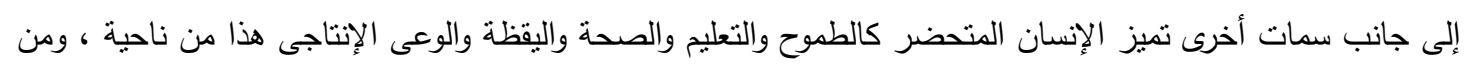

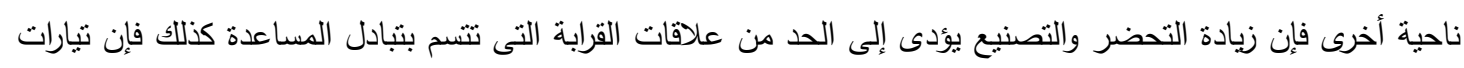

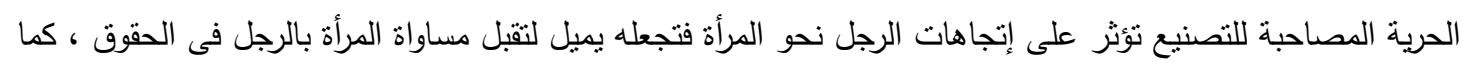

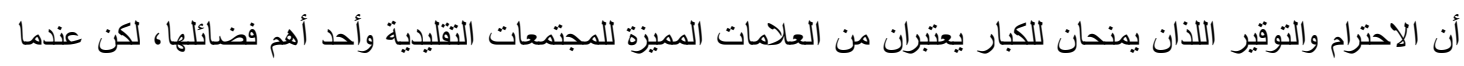

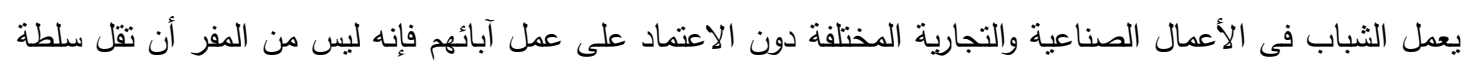



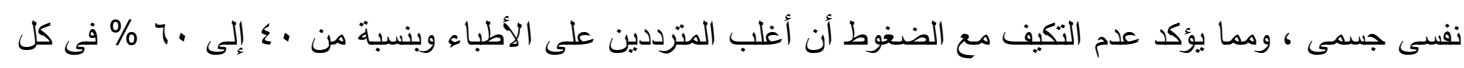



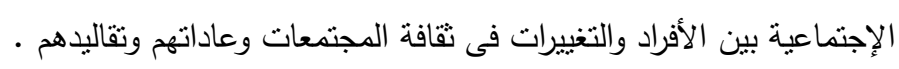

كل ذلك أدى إلى زيادة القلق والصراع و التتافس القاتل بين الأفراد فضلا عن الظروف الإقتصادية القلقة والبطالة والتهديد

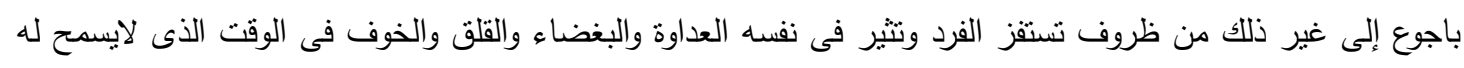
بالتعبير عن هذه الإنفعالات تعبيرا صريحا ـ كل ذللك يعد سبيا فى نمو وتزايد الاضطرابات السيكوسوماتية لدى الإنسان

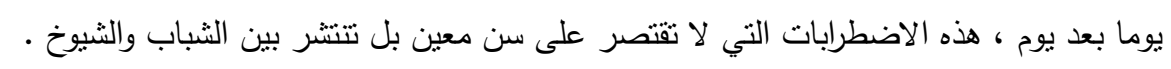
ويؤكد "هاليدى " أن هذه الاضطرابات صارت اليوم منتشرة بين الثباب أكثر منها لدى الثشيوخ ، ومما يؤكد ذلك مايذكر

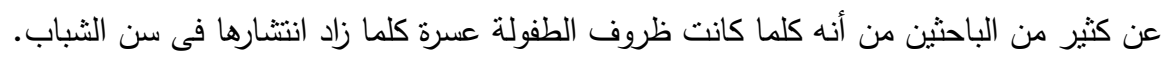
-ففى ظل هذه الظروف الحياتية التى يعيشها إنسان اليوم وتعقد أسليب العيش فيها ، والتغير السريع المتلاحق التى أصبح

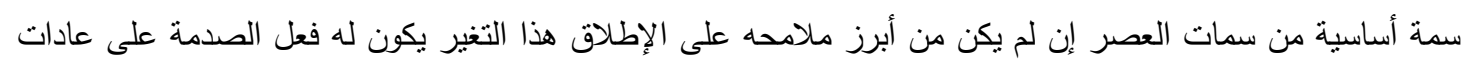

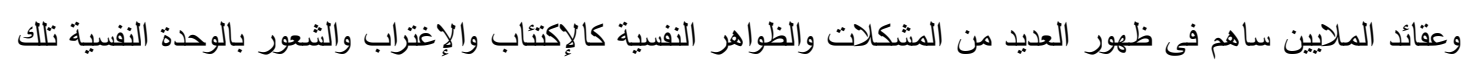

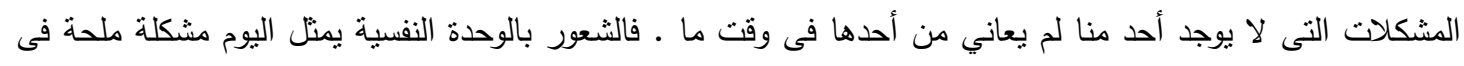

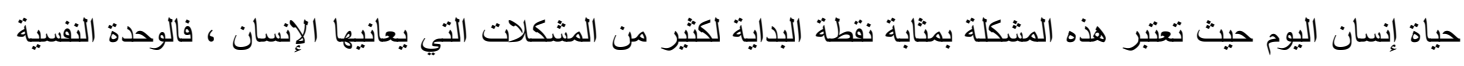

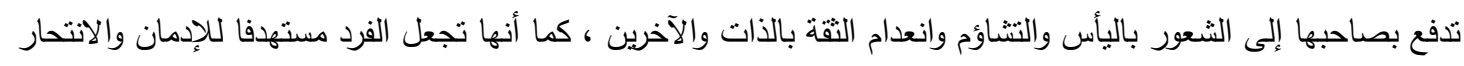








من هنا باتت ظاهرة الوحدة النفسية مشكلة تتطلب المزيد من جهد الباحثين وتفكيرهم للكثف عن طبيعتها ومسبياتها وسبل

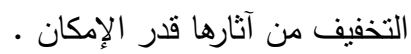

-ومن هنا كان اهتمام الباحثة بدراسة الثعور بالوحدة النفسية وعلاقتها بالأعراض السيكوسومانية لدى عينة من طالبات



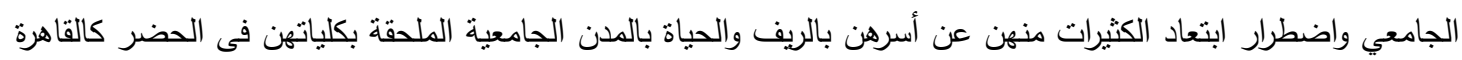

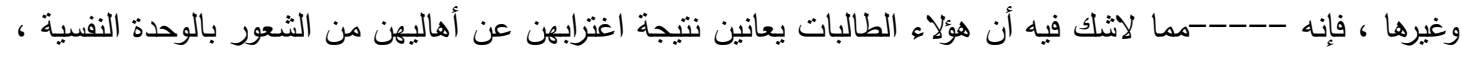



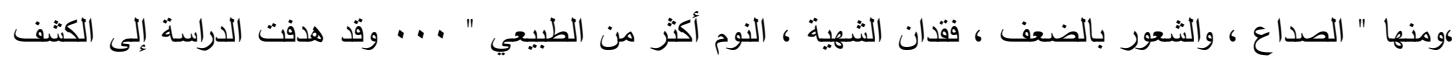

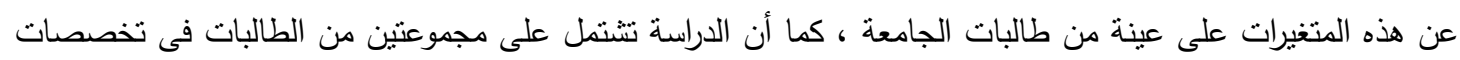

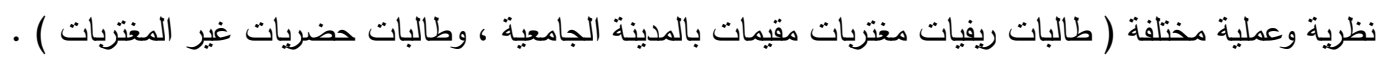

$$
\text { - وبناءا على هذا يكون موضوع البحث الحالي: }
$$

دراسة مقارنة فى الأعراض السيكوسوماتية بين طالبات الجامعة الريفيات المغتربات بالمدينة الجامعية والطالبات غير

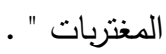
ومن هنا يكون النساؤل الرئيسي بالبحث الحالي كالتالي : 1- هل هناك فرق له دلالة إحصائية في متغير الأعراض السيكوسوماتيبة بين المغتربات وغير المغتربات- من

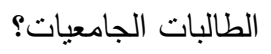

\section{أهمبة الدراسة:}

$$
\text { يستمد البحث الحالي أهميته- النظرية والتطبيقية- علي النحو التالي: }
$$

الأول: ينعلق بظاهرة الأعراض السيكوسوماتية من حيث أنها ظاهرة ازداد نواترها في عصرنا هذا الدحمل بالأعباء بسبب

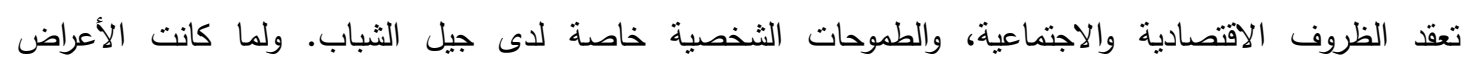



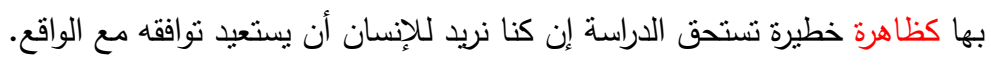
الثاني: إن معظم الدراسات التي تتاولت الأعراض السيكوسوماتية ركزت علي بعضها دون البعض الآخر ، بينما نحاول هذه

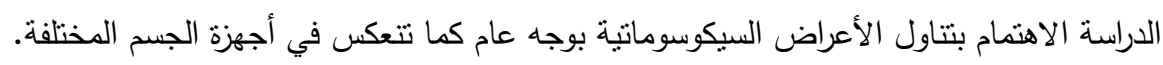

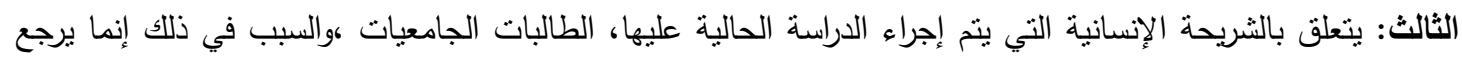



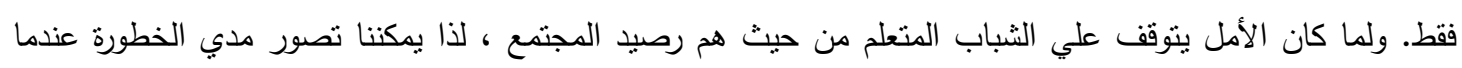




منهن إفراز جيل واع متعلم متوافق نفسياً واجنماعياً وجسمياً. 


$$
\text { (محمود السيد أبو النيل: ؛ } 99 \text { 19، . 19) }
$$

أهداف البحث الحالي وموضعها بين الدراسات:-

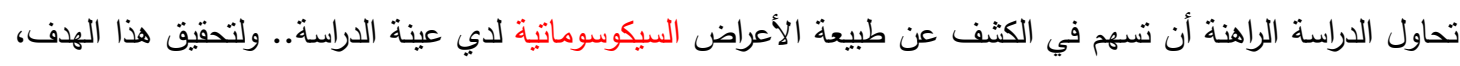

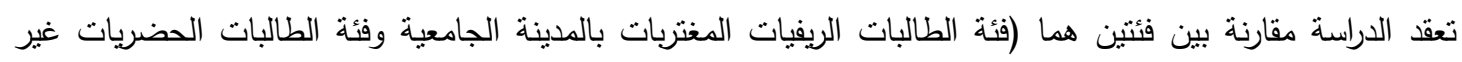

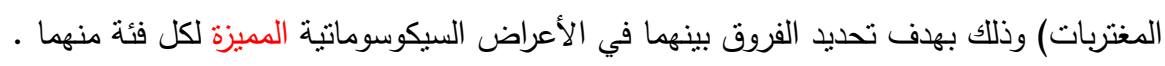

- وعلي هذا الأساس تتدرج الدراسة الراهنة ضمن المحاولات التي تبذل للكثف عن الأسباب المؤدية للإصابة بمختلف الأمراض النفسجمية. فرض البحث :

1-يوجد فرق له دلالة إحصائية في الأعراض السيكوسوماتية بين الطالبات الريفيات المغتربات بالمدينة الجامعية و بين الطالبات العضريات غير المغتربات.

عينة الدراسة : ( ) أجريت الدراسة الحالية على عينة يصل عددها الى مائة طالبة مقسمات الى مجموعتين: مجموعة غير المغتربات ( V - T r ع عاما ) ويصل عددهن الى .0 طالبة. أدوات الدراسة:

أعتمدت الباحثة على الأدوات الآتية للتحقق من أهداف الاراسة: ( ) ق ائمة كورنل الجديدة للنواحى العصابية والسيكوسوماتية.

تأليف: كيف برودمان ،البرت ج.اردمان ،هارولدج.ولف 191

تعريب واعداد: الاكتور .محمود السيد أبو النيل ه9 199

$$
\text { نتائج البحث : }
$$

أسفر البحث الحالي عن النتائج التالية :

قبل عرض نتائج الفرض قامت الباحثة بتحليل احصائي للاختبارات الفرعية لقائمة كورنل للأعراض السيكوسومانية و

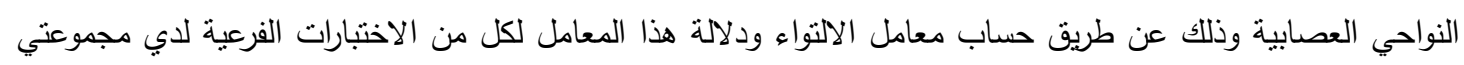


جدول (1 ) التحليل الإحصائي للاختبارات الفرعية و الارجة الكلية لقائمة كورنل للنواحي العصابية و السيكوسوماتية ل اللمجموعة المغتربات

\begin{tabular}{|c|c|c|c|c|c|c|}
\hline مستوي الدلالة & الالتواءة معامل & معامل الالتواء & الوسيط & الانعياري & المتوسط & الاختبارات \\
\hline غيردال & $1, Y$ & - ، \&Y. & $\varepsilon$ & Y.00 & \&,rk & السمع \\
\hline غيردال & $r, 11$ & $.6 \mathrm{~V} \leqslant 1$ & $\varepsilon$ & r.AO & 2607 & الجهاز \\
\hline غيردال & 1,91 & .6794 & $r$ & Y.9Y & $r, q$ & القلب \\
\hline دال & Y, & . 6949 & r & Trtr & 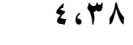 & الجهاز \\
\hline غيردال & Y, ؛ & . ‘A & Y.O. & T.ITY & r.71 & الهيكل العظمي \\
\hline غيردال & $\cdot, \leqslant 7$ & & $r$ & $Y_{6}, Y_{1}$ & Y.q & الجلا \\
\hline غيردال & 1,09 & .001 & $\varepsilon$ & $r_{6} \cdot r_{\varepsilon}$ & 4.74 & الجهاز \\
\hline غيردال & $r, Y_{1}$ & . $\mathrm{VVO}$ & r & YGVYA & r.q $\&$. & البولي \\
\hline غيردال & $\cdot, \cdot 1$ & $\cdots$ & $r$ & $1.91 \%$ & r.l r. & التعب \\
\hline غيردال & $r, \ldots r$ & $.6 \mathrm{~V} .1$ & $\bar{r}$ & $Y_{6} l \leqslant 0$ & Y.V $\leqslant$ & تكرار المرض \\
\hline دال & $\varepsilon, 00$ & 1,095 & $r$ & 96109 & r,Y & أمراض \\
\hline دال & $\varepsilon, V Y$ & $1,70 \%$ & $\mu_{6} \theta$ & r.VOV & $\varepsilon_{G, Y . .}$ & العادات \\
\hline غيردال & $1, r q \leq$ & . $، \leqslant \wedge \wedge$ & $\varepsilon$ & $r_{6} .9$. & 0 & عدم الكفاية \\
\hline غيردال & 1,0 & . & $r$ & 1.170 & Y.T... & الاكتئاب \\
\hline غيردال & $1, .7$ & $.6 \mathrm{rVI}$ & $\varepsilon$ & Y.099 & r.o. & القلتي \\
\hline غيردال &., $99 \mathrm{~V}$ & $.0 \% \leqslant 9$ & r & I.V $\leqslant$. & $Y_{6} \leqslant \Lambda$. & الصساسية \\
\hline غيردال & $1, V M_{1}$ & .67 .7 & $r$ & Y. $\leqslant 49$ & r.r. & الفضب \\
\hline غيردال & $1, V M I$ & 9.97 & $\varepsilon$ & $Y_{6} \leqslant \leq \leqslant$ & 2.17. & التوتر \\
\hline غيردال & $1, \mu q$ & $\cdot, \leqslant \vee 7$ & 71 & $r Y, V \wedge$ & $70,0 Y$. & الارجة الكلية \\
\hline
\end{tabular}

يتضح من الجدول ( 0 ) أن معامل الالتواء لم يصل الي مستوي الدلالة في أبي من الاختبارات الفرعية لقائمة كورنل للأعراض السيكوسومانية سوي علي كل من الاختبارات الفرعية للجهاز الهضمي و العادات و الأمراض المنتوعة حيث 



لصعوبة بالنسبة لتلك المجموعة . جدول ( ) التحليل الإحصائي للاختبارات الفرعية و الارجة الكلية لقائمة كورنل للنواحي العصابية و السيكوسوماتية للمجموعة لغير المغتربات

\begin{tabular}{|c|c|c|c|c|c|c|}
\hline مستوي الدلالة & الالتواء & معامل الالتواء & الوسيط & الالحعراف & المتوسط & الاختبارات \\
\hline دال & r,Tr & $.69 Y Y$ & $r$ & Tr $\varepsilon \varepsilon$ & T.QY & الابصمع \\
\hline غيردال & 1,04 & $.60 \mathrm{TV}$ & $\Gamma$ & T.rq & $r_{6} V$ & التنفسي \\
\hline غير دال & •, YYY & $\because \vee \wedge A$ & $\varepsilon$ & r.OT & r.T & الأوعية \\
\hline غيردال & Y,O & $.6 \wedge 9 Y$ & $r$ & 1619 & T.AY & الجضهي \\
\hline دال & $\varepsilon, \wedge$ & $1,7 \wedge$. & 1 & $T_{6} \leqslant 0$ & $T_{61}$ & الهيكل العظمي \\
\hline دال & $Y, \wedge Y$ & .6919 & 1,0 & $1 . \mathrm{VV}$ & $Y_{6} \cdot Y_{T}$ & الجلا \\
\hline غيردال & $1,7 \mathrm{VV}$ & $.60 \wedge \mathrm{V}$ & $r$ & T.VT & $r_{6} \varepsilon \Lambda$ & العصبي \\
\hline دال & $\varepsilon, Y \cdot O$ & $1, \varepsilon V Y$ & $T$ & YGYY & $1, V \varepsilon$ & التناسلي \\
\hline غيردال & $1, \cdot \varepsilon$ & . 6477 & r.O. & $1, \wedge \varepsilon$ & Y.TE & التعب \\
\hline دال & $\varepsilon, .0$ & $1, \varepsilon Y$. & 1.0. & T.TV & TGYY & تكرار المرض \\
\hline دال & $r, v 1$ & $1,4 \ldots$ & Y & r.VI & T.V. & متنوعة \\
\hline دال & $r, 1 \varepsilon$ & 16.99 & $\mu$ & T.9T & $r$ r. r & العادات \\
\hline غير دال & $\cdot, \leqslant \leqslant 0$ & .6107 & 0 & TGMT & $\varepsilon_{6} \vee \wedge$ & عدم الكفاية \\
\hline غيردال & $1, \wedge \varepsilon$ & $.67 \leq 7$ & 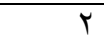 & $1, \wedge \varepsilon$ & r.IY. & الاكتئاب \\
\hline غيردال & T,YYY & . 'AIT & $r$ & T.Y & Y.YA. & القلق \\
\hline غير دال & I, ITV & . $6 \leqslant 7 \wedge$ & r & $r_{6} \cdot \varepsilon$. & T.Y. & الحساسية \\
\hline غير دال & $r, I I V$ & $\cdot 6 V \leqslant 1$ & $r$ & T.99 & T.VA & الغضب \\
\hline غيردال & r, rAY & . ‘ATE & r & $r_{6} \leqslant q$. & T.T. & التوتر \\
\hline
\end{tabular}




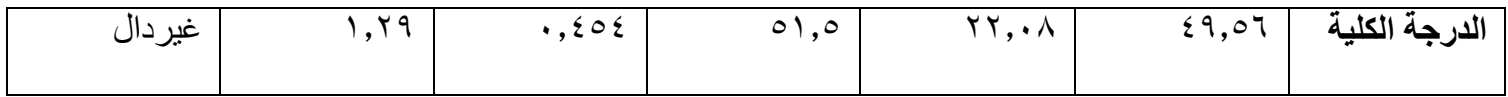

يتضح من الجدول ( 1 ) ) أن معامل الالتواء قد وصل إلي مستوي الدلالة الإحصائية علي كل من مقاييس السمع و

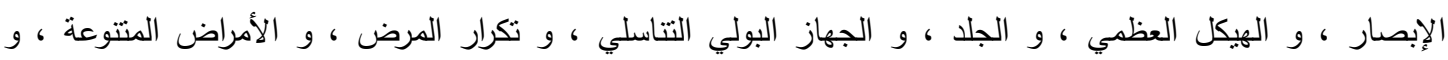

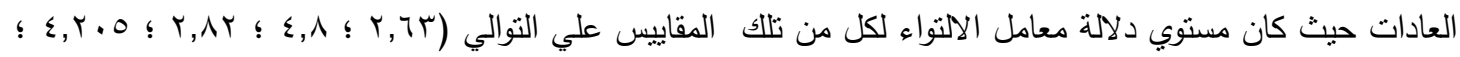

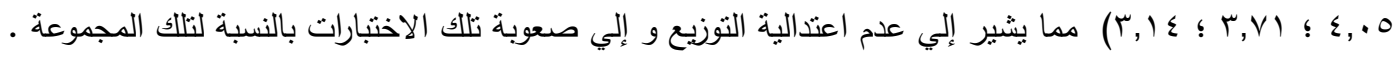

جدول ( ب ) الفروق بين مجموعة الطالبات الريفيات المغتربات بالمدينة الجامعية وبين مجموعة الطالبات الحضريات

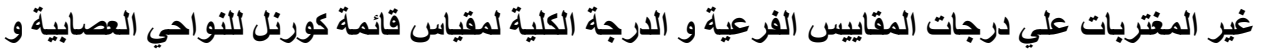
السيكوسوماتية

\begin{tabular}{|c|c|c|c|c|c|c|c|}
\hline \multirow[t]{2}{*}{ الدلالة } & \multirow[t]{2}{*}{ القيمة الحرجة } & \multirow[t]{2}{*}{ قيتنة مان } & \multicolumn{2}{|c|}{ مجموعة غير } & \multicolumn{2}{|c|}{ مجموعة المغتربات } & \multirow[t]{2}{*}{ الاختبار } \\
\hline & & & مجموع الرتب & متوسط الرتب & مجموع الرتب & متوسط الرتب & \\
\hline $.6 \cdot 1$ & $r_{6} \cdot \leqslant 9$ & 111,0 & $r \cdot \Lambda T_{6} 0$ & $\sum 1, V T$ & r97r.0 & $096 \mathrm{TV}$ & السمع و الابصار \\
\hline غيردال & I.TrY & $1.01,0$ & THMT.O & $\sum 7.7 V$ & $T V 17,0$ & $0 \leqslant$ OKT & الجهاز التنفسي \\
\hline غيردال & $\cdot 6 \cdot 87$ & Trrq & YOI & $0.6 \mathrm{YA}$ & rory & $0.6 V Y$ & القلب و الأوعية \\
\hline .6 .0 & $Y_{6} \varepsilon r \varepsilon$ & 9.1 & YIVT & $\sum r_{6} 0 Y$ & $Y \Lambda_{6} V \varepsilon$ & $O V_{6} \leqslant \Lambda$ & الجهاز الهضمي \\
\hline $.6 \cdot 1$ & $r .9 \leq 7$ & $\Lambda Y \Lambda_{6} 0$ & r).r.0 & $\varepsilon r_{6} \cdot V$ & $r 9 \leq 7,0$ & $0 \wedge .94$ & الهيكل العظمي \\
\hline .6 .0 & r.rOQ & $91 \pi$ & rIAN & $\varepsilon r_{6} \vee \tau$ & TATr & $O V_{6} T \leq$ & الجلا \\
\hline .6 .0 & 1.91. & $97 \leqslant 60$ & TrMq,0 & $\varepsilon \varepsilon 6 \vee 9$ & $r \wedge 1 \cdot .0$ & 07.41 & الجهاز العصبي \\
\hline .6 .0 & $r_{6} \leqslant 09$ & 9.1 & rIVT & $\varepsilon r_{6} O T_{1}$ & TAV乏 & $\Delta V_{6} \leqslant \Lambda$ & البولي والتناسلي \\
\hline .6 .0 & $1.9 \times 0$ & $97 V$ & $T Y \leqslant Y$ & $\varepsilon \varepsilon_{6} \wedge \varepsilon$ & $r \wedge \cdot \Lambda$ & 07.17 & التعب \\
\hline غيردال & 1.741 & $1.1 \mathrm{~V}$ & TrAT & $\leqslant 0, \wedge \leqslant$ & TVON & 00,17 & تكرار المرض \\
\hline غيردال & .6974 & $111 \mathrm{r}$ & THAV & $\varepsilon V_{6} V \leqslant$ & (T) & Or.YT & أمراض متتوعة \\
\hline غيردال & $1, \mathrm{VA1}$ & $99 \leq$ & rYT9 & $\sum 0,4 \Lambda$ & TVAI & $00,7 \mathrm{~T}$ & العادات \\
\hline غيردال & .6174 & ITYT & $10.1,0$ & $0.6 . T$ & $r 0 \leq \Lambda_{6} 0$ & $0.69 V$ & عدم الكفاية \\
\hline غيردال & .0011 & $11 \mathrm{VV}$ & $r \leqslant O Y$ & $\leqslant 96 . \leqslant$ & ro91 & 01,97 & الاكتئاب \\
\hline .6 .0 & T.OYT & $\wedge \wedge \wedge$ & rוTr & $\sum Y_{6} Y T$ & TANV & $0 V_{6} V \leq$ & القلق \\
\hline غيردال & $.691 \leq$ & 1119.0 & $r r q \leq 00$ & $\sum V_{6} \wedge 9$ & $r 700,0$ & 04,11 & الحساسية \\
\hline غيردال & $1, \leqslant 71$ & $1 \cdot 6 \varepsilon$ & TrIO & $\sum$ E.T. & TVMO & $0 \varepsilon_{6} V$. & الغضب \\
\hline$\cdots \cdot 1$ & $r .19 r$ & 189.60 & $Y .70,0$ & $\sum 1,41$ & $r q \wedge \varepsilon_{6} 0$ & 09679 & التوتر \\
\hline.$\cdots 1$ & T.MY & 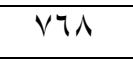 & $r \cdot \varepsilon r$ & $\varepsilon \cdot 6 \wedge 7$ & $r \ldots v$ & $7.61 \leq$ & اللارجة الكلية \\
\hline
\end{tabular}

يتضح من الجدول ( (1) ) أن نتائج التحليلات الاحصائية التى أجريت باستخدام اختبار مان-ويتتى أنثارت إلى وجود فروق ذات دلالة إحصائية بين المجموعتين ( الطالبات الريفيات المغتربات بالمدينة الجامعية ، والطالبات الحضريات غير المغتربات ) علي كل من المقاييس الفرعية للسمع و الابصار و الهيكل العظمي عند مستوي دلالة ا.،.. ، والجهاز

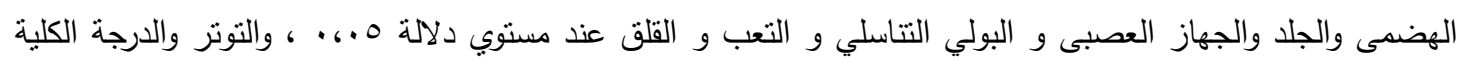
عند مستوي دلالة ا (... • باتجاه المغتربات .

وهذا يشير إلى معاناة الطالبات الريفيات المغتربات المقيمات بالمدينة الجامعية (عن الطالبات الحضريات غير المغتربات) من الثكاوى والأعراض السيكوسوماتية التي تختص بضعف الإبصار كالحاجة لنظارة واحمرار العينين والتهاباتها وآلامها 


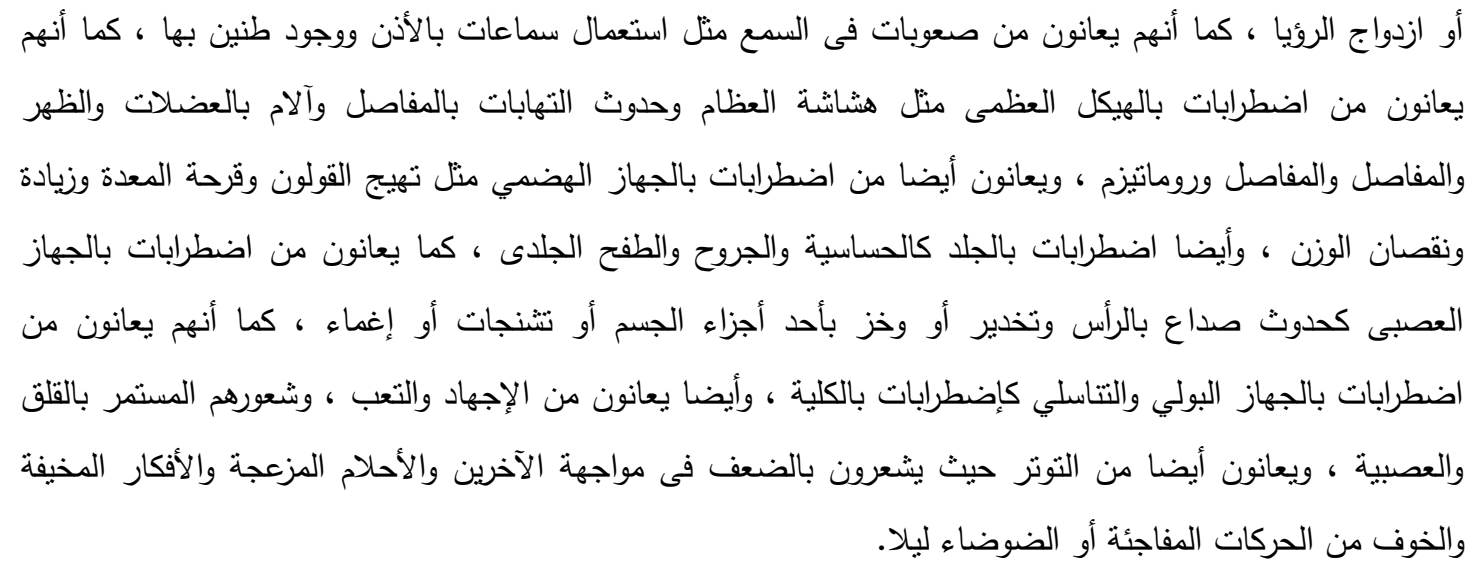

\section{Summary}

\section{Importance of the research :}

The current research is important theoretically \& practically for the following reasons:

(1) Prevalence of psychosomatic symptoms among young people because of the complexity of the economic and social conditions and personal ambitions.

(2) Most previous studies have focused on some psychosomatic symptoms without others while the current study trying to interest in addressing psychosomatic symptoms in general as reflected in the various systems of the body.

\section{Research aims :}

The current research aims to detect psychosomatic symptoms among female expatriate students and non-expatriate.

\section{Research hypotheses :}

(1)There is a statistically significant difference between the rural female expatriate students at expatriate housing of university and urban female non-expatriate students on psychosomatic symptoms .

\section{Sample of the Research :}

The current study involved 100 female students divided into two groups as follow : The first group consists of 50 expatriate female students ranging from (17-21) years. The second group consists of 50 non expatriate female students ranging from (17-23) years .

\section{Research tools :}

(1)List Cornell's new aspects of neurotic and psychosomatic (Localization and preparation Abu Al nail).

\section{Results :}


(1) The results of the first hypothesis indicated that there are statistically significant differences between the expatriate and non-expatriate female students on each of the subscales of hearing and vision, and the skeleton and digestive system and the nervous system and skin and urinary tract and fatigue and anxiety and tension, and the total score towards expatriate female students. 
قائمة المراجيع

أولا : المراجع العربية

1- أحمد عزت راجح (Y V I I ) : الأمراض النفسية والعقلية - أسبابها وعلاجها وآثارها الاجتماعية ، دار المعارف ،

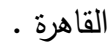

2-أيمن غريب قطب ناصر (11 + r) : سيكولوجية التحديث وتحديات العولمة - آفاق نظرية ورؤى تربوية ، مكتبة الأنجلو المصرية ،القاهرة .

3- حامد عبد السلام زهران (9 9 1 ) :الصحة النفسية والعلاج النفسي ، الطبعة الثالثة ، عالم الكتب ، القاهرة .

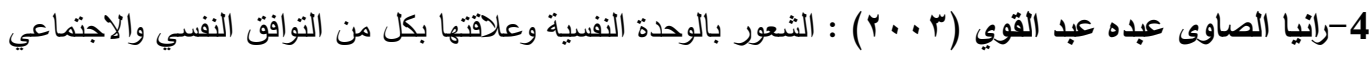

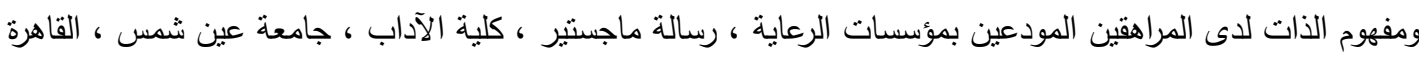

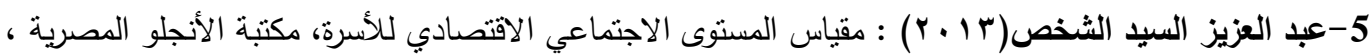
القاهرة. 6-فرج عبد القادر طه وشاكر قتديل وآخرون (ب9 9 1 ) : موسوعة علم النفس والتحليل النفسي ، الطبعة الأولى ، دار

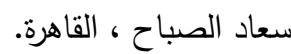
7-مجدى محمد الدسوقي (991 (1)) : مقياس الثعور بالوحدة النفسية ،مكتبة الأنجلو المصرية ، القاهرة.



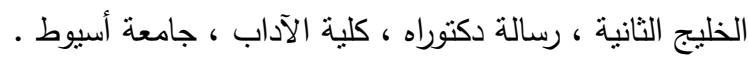
9-محمود السيد أبو النيل (ـ 99 ) : الأمراض السيكوسومانية في الصحة النفسية ، المجلد الأول ، الطبعة الثانية ، دار النهضة العربية ، بيروت . 10 - محمود السيد أبو النيل (؛ 9 9 1) : الأمراض السيكوسوماتية - دراسات وبحوث عربية وعالمية ، الدجلد الثاني ، الطبعة الثانية ، دار النهضة العربية ، بيروت .


القاهزة . 12-محمود السيد أبو النيل (ع . . ץ) : الصحة النفسية ، كلية الآداب ، جامعة عين شمس ، القاهرة 13-محمود السيد ابو النيل (9 . . ץ) : الإحصاء النفسي والإجتماعى والتزبوي، الطبعة السابعة ، القاهرة . ع ا-محمود عبد القادر محمد ( IVVV) :دراستان في دوافع الإنجاز و سيكولوجية التحديث للثباب الجامعي، مكتبة الأنجلو المصرية ،القاهرة. 15- منى حسين حسن أبو طيرة (919 19) : علاقة الاضطرابات السيكوسومانية بالثخصية والتتشئة الإجتماعية لدى طلاب الجامعة ، رسالة دكتوراه ، كلية الآداب ، جامعة عين شمس ، القاهرة . 16- منى كامل عبد الله محمود (199 1 ) : المتغيرات الثخصية والاجتماعية المرتبطة بالإحساس بالوحدة النفسية لدى طلاب المدن الجامعية بجامعة الإسكندرية ، رسالة ماجسنير ، كلية التربية ، جامعة الإسكندرية . 17-مرفت حبيب عبد السلام خليفة (r ا ـ ץ) : الصفحة النفسية لذكاء المسنين ، رسالة دكتوراه ، كلبة الآداب ، جامعة 
18-نبيل السمالوطى ( •99 1) : التتمية والتحديث الحضاري- تحليل الأبعاد النفسية والاجتماعية للتنمية الاقتصادية ،

الجزء الأول ، مطبعة الجبلاوى ، القاهرة.

19- نجوى عبد الله أحمد (ع r) : فعالية برنامج إرشادي عقلانى إنفعالى في خفض درجة الثعور بالوحدة النفسية

لاى عينة من طلاب الجامعة ، كلية الآداب ، جامعة عين شمس ، القاهرة

ثانيا : المراجع الأجنبية

1- Frankenhaeuser,Marianne,Lundberg,Uif,fredrikson, mats,Melin ,Bo et al0,(oct., 1989),Stress on And off the Job as related to sex and Occupational

Status in white - Collar Workers, Journal of Organizational BehaVior, Vol.10

(4):321-346

2- Howard , J.H., Cunningham, D.A.\& Rechnitzer P.A.,(Dec., 1984), Physical ActiVity as a Moderator of life Events and Somatic Complaints : Alongitudinal Study,Can J.Applied Sport Sci.,(4).

3- LeonoVa,Anna,B.,(1996),Occupational stress,Personal Adaptation and Health,Psychology professional and Research,(1997),Book Source:Spielberger, Charles Donald(Ed.),Sarason Irwin G.(ed.) et al.,(1996),Stress and Emotion : Anxiety,Anger,and Curiosity,Vol.16,Series in Stress and Emotion,(PP109-125) DC.,Taylor\&Franci Xvi,315pp,U.S.A

4- Moroi.K.,:"'Loneliness induced by Situation Changes in the lives of Experimental Social Psychology(Feb.,)Vol.25(2),(1980)pp.115- 125

5- Pharr-Ann-E.,(1988), Effects of Stress on Women Managers in Washington D.C.GoVernment,PH.D.,UniVersity of Pittsburgh,(178)

6- Sime,WE.,Rossi,AM.\&Lubbers,CA.,(1990),Incidence of Stress-Related disorders among American and Brazilian Men and Woman,International Journal of Psychosomatic,37(1-4):7-62

7- Voux,A:"Social and Personal Factor in Loneliness", Journal of Social \& Clinical Psychology,Vol.613-4,(1988)pp.462-471 
